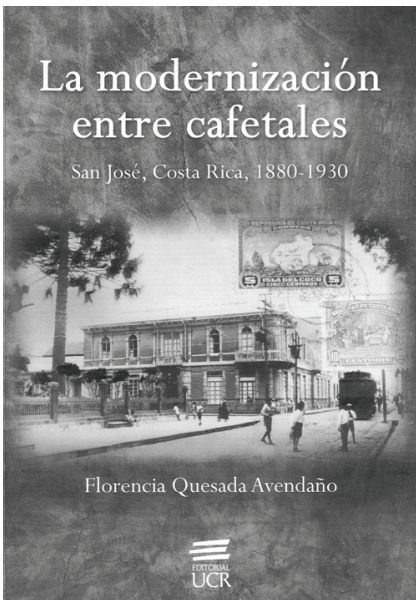

¿Por qué y cómo se puso en marcha el proceso de modernización de San José entre 1880 y 1930 ? Tal es la interrogante central que aborda la historiadora costarricense en este contundente estudio que examina tanto los aspectos materiales de la ciudad, su transformación cultural y el contexto ideológico como las representaciones de la imagen y de la modernidad estética urbana que en ella se despliegan. Se trata de una interpretación crítica del proceso de cambio de esta pequeña y periférica capital centroamericana y de su renovación a partir de las últimas dos décadas del siglo XIX. De ahí que su primera contribución a la historiografía latinoamericana se vincule al periodo y lugar escogidos.

El arco temporal del estudio es pertinente y relevante para la propia capital cafetera,
LA MODERNIZACIÓN ENTRE CAfetales. San José, Costa Rica, 1880-1930

Florencia Quesada Avendaño

Editorial de la Universidad de Costa Rica, 2011

por cubrir un lapso en el cual, con diversos matices, se desarrollaron procesos similares en la región. Las décadas que examina esta monografía corresponden a esa etapa de las ciudades latinoamericanas que José Luis Romero ha denominado como de "ciudades burguesas". En el caso de Costa Rica, se trata de una fase clave - como señala Quesada- en su proceso de centralización política, durante la cual la burguesía josefina expresó valores sociales y morales mediante la renovación y control del espacio urbano. Se abordan desconocidos capítulos de esta capital centroamericana, de fundación colonial tardía y que solo adquirió relevancia a escala nacional tras la Independencia. El estudio logra esbozar algunos procesos de la agenda urbana josefina en relación con ciudades vecinas -Ciudad de Guatemala o La Habana- e incluso más lejanas, como Lima, 
Montevideo y Buenos Aires, y los pone en la perspectiva de la formación de los Estados Nacionales.

Una segunda contribución se relaciona al original enfoque del trabajo. La referencia a Henri Lefebvre de la cual arranca este libro, quien concibe la ciudad como un espacio producido por relaciones de personas, y no de objetos, bien refleja el sentido de esta valiosa investigación. Desde esta perspectiva es que el estudio sitúa la capital como escenario de desarrollo del proyecto de Estado Nación y civilizatorio, fenómeno no poco conocido para el contexto latinoamericano. De ahí que sea relevante interrogar cómo este trabajo se constituye en un aporte para comprender cómo un gobierno local y central participa activamente en el tránsito de una ciudad colonial a su reedición republicana. Y la respuesta la encontramos no solo en el hecho de tratarse de una ciudad hasta ahora poco estudiada en la historiografía urbana, sino también en la evidente contribución de su novedosa perspectiva, la que recoge la producción social del espacio para abordar el tema. El acercamiento cultural al fenómeno urbano brinda una nueva concepción de ciudad y de segregación socioespacial en la que -según declara la autorase entiende la construcción de un espacio social del poder. Una tal aproximación a la ciudad como sujeto, indudablemente enriquece la mirada de los estudios sobre capitales latinoamericanas.

Una tercera contribución es la metodología que utiliza el estudio, con consulta a fuentes de diversa naturaleza que incluyen un amplio repertorio de material impreso, documentación oficial de archivos locales y extranjeros, a la vez que registros icnográficos y literarios, oficiales y de viajeros. La rigurosa operación de análisis de este material que realiza la autora en su conjunto resulta en una interpretación crítica y del proceso estudiado.
Como evidente aporte para la historia cultural y urbana, y para los estudios urbanos en general, este libro se inserta en una fresca y vigente historiografía. Se inscribe, por una parte, en los crecientes estudios de microhistoria que han fortalecido la producción de monografías urbanas; y por otra, en la mirada de la historia urbana latinoamericana, que entiende la ciudad como objeto cultural que produce significaciones. En este sentido, el estudio constituye una propuesta de historia urbana cultural en la que modernización y espacio son los sujetos principales del estudio.

El primer capítulo, “Antecedentes”, además de referir a los capítulos de la transformación josefina en un marco temporal más amplio y que es relevante en la medida de su tardía fundación, se constituye como una rigurosa revisión histórica de los orígenes y asentamientos primarios de San José y de su transición de poblado colonial a capital republicana. La autora urde en un armónico relato -que incluye testimonios escritos de viajeros-aspectos materiales como la forma en que se implantaron algunos rasgos de la ciudad colonial, la grilla, la plaza y el mercado, con modos de vida del asentamiento colonial.

En su análisis, Quesada releva el impulso de la ciudad bajo las reformas borbónicas y cómo, al promediar el siglo XIX, San José ya había dado los primeros pasos hacia su modernización mediante la construcción de edificios públicos, infraestructura, espacios públicos, incorporación de alumbrado, entre otros avances, mientras el café ya aparecía como la base de su economía.

En el segundo capítulo, denominado "Ideología”, la historiadora indaga en el modo en que la elaboración de nuevos contextos materiales, como forma de modernización y progreso por parte de autoridades municipales, reflejó la puesta en práctica de la ideo- 
logía liberal y positivista y de las propuestas higienistas. La autora se refiere a importantes capítulos de la transformación urbana, entre los que destacan los proyectos de ensanche -en sus distintas etapas y bajo el liderazgo de diferentes actores-, la creación de los primeros barrios de elites y sectores medios fuera de la cuadrícula colonial.

En el enfoque planteado por Quesada, la inauguración del progreso en el marco del crecimiento y transformación de San José permite constatar cómo la renovación urbana fue la expresión material de la reorganización de un espacio social del poder. Progreso y modernización se elaboraban en forma segregada, en cuanto el sur y noroeste de la capital quedaban rezagados del proyecto modernizador. De este modo, la autora contribuye a ampliar la reflexión sobre cómo se entendía el progreso en aquellas décadas, cómo fue su puesta en práctica en la escena urbana y cómo se pueden trazar ciertos orígenes de una capital segregada.

Un rol central como impulsor de las transformaciones urbanas ocupó el higienismo, cuestión que se analiza en el tercer capítulo, "Higiene", donde se pone atención a una importante dimensión de la modernización urbana de fin de siglo en Latinoamérica. Al igual que en otros contextos de la región, el círculo de higienistas impulsó reglamentos, instituciones y formas de organización que apuntaron a controlar el espacio urbano en nombre de la higiene y de la salud pública.

Distinguiendo el rol de los profesionales y los elementos de ese discurso como parte del equipaje civilizador, el estudio se concentra en el proyecto de construcción de alcantarillado, el mejoramiento de cañerías, los protocolos higiénicos para edificios colectivos y privados, la posterior pavimentación en asfalto y la expansión de áreas verdes en la ciudad. La historiadora examina los proyectos de saneamiento en sus di- ferentes etapas, sin perder el foco de que la higienización de la ciudad también elabora un espacio socialmente diferenciado. Las mejoras en la infraestructura sanitaria no solo tuvieron mayor impacto en la capital que en el resto del país, sino que, dentro de la misma, esta dotación se concentró en su interior y solo avanzó en etapas posteriores a espacios habitados por sectores populares.

La puesta en marcha de estos cambios es examinada en el capítulo cuarto, "Transformaciones”, en la que la autora se aproxima a la creación de parques, bulevares y monumentos públicos que no operan únicamente como respuestas a las demandas del higienismo en pos de mejorar las condiciones de vida urbana, sino también como espacios sociales donde se articulan relaciones de poder, y cuya ubicación dentro de la ciudad les otorga una cierta jerarquía. Interesa la forma en que estos espacios modelan los modos de habitar la ciudad, las celebraciones y la vida cotidiana, como dimensión del espacio público moderno que plasma las formas, mensajes y modos de vida de la sociedad josefina. Parques, bulevares, plazas y plazoletas puestas en el escenario de ideales modernizadores -especialmente en San José, que careció de paseos y alamedas arborizadas durante el periodo colonial- son comprendidos por Quesada en el debate que grafica diferentes tensiones: entre modernidad y tradición, entre elites y sectores populares, y entre centro y periferia. En otras palabras, estos espacios se entienden en lo que la autora llama "espacios sociales de poder".

Mientras los primeros cuatro capítulos refieren a las transformaciones urbanas y su sentido, así como a los principales actores $\mathrm{y}$ formas en las que se pusieron en marcha, los dos capítulos finales ponen el foco en la representación e imaginarios de la ciudad en el marco de estos cambios. El capítulo cinco, "Imaginarios foráneos y locales", se 
concentra en la lectura que hicieron de la ciudad viajeros europeos y norteamericanos por medio de sus descripciones, mirada que se nutre también de guías oficiales, directorios y otras fuentes locales. Estos relatos, que principalmente se refirieron a la capital del país, destacaron el valor del paisaje que constituía el entorno de la capital y, en alguna medida, la generación de una desilusión frente a su estilo colonial. Los relatos dieron cuenta de la pervivencia de un aspecto urbano colonial -especialmente su damero y construcciones de adobe y teja-, mezclado con modernos edificios, nuevos servicios públicos, arquitectura ecléctica, áreas verdes y un vital comercio. La interpretación de la autora sostiene que estas representaciones crearon una visión ideal y limitada a los espacios físicos y modos de vida de la ciudad burguesa. Los viajeros escasamente señalaron la existencia del mundo popular, creando un imaginario de una ciudad limpia e higiénica, democrática, blanca y ordenada, representación que se reducía a los espacios donde habitaron los sectores más privilegiados.

"Imaginarios fotográficos", título del capítulo seis, sitúa la fotografía como instrumento que nutrió el discurso del progreso y civilización urbana. Estas fuentes son examinadas como un medio que promovió una cierta imagen "moderna" de la ciudad, al servicio de la construcción de un imaginario urbano nacional basado en valores como orden y progreso. Visto así, este capítulo plantea una serie de cuestiones metodológicas en la línea del valor que tiene la fotografía como fuente para la historia urbana; no solo como reflejo -con todas las limitaciones que implica- de una realidad, sino también en su rol de contribuir a la creación y construcción de una imagen de la misma.

Mediante la fotografía, la autora incorpora y refuerza algunas formas en la que se puso en práctica la idea de progreso. Su interpretación respecto de la visión que resulta de las imágenes confirma el registro de la ciudad burguesa, mientras la ciudad miserable quedaba ausente. En cuanto a aquellos elementos que son fotografiados, existe una evidente coincidencia con las tareas que el discurso modernizador liberal de fines del siglo XIX concretó. Se trataba de la arquitectura de edificios públicos, civiles y religiosos, destacadas residencias particulares, parques y espacios públicos, adelantos técnicos como el tranvía o el ferrocarril, y las vistas panorámicas que coincidían con la imagen que viajeros habían dejado estampada de la ciudad construida en cuanto inseparable de su entorno. Así, a partir de fuentes fotográficas, la autora mantiene la concepción del espacio social como medio de control y de dominación, que se refleja en la ciudad no representada, la ciudad de sectores populares y medios - en sus barriadas y modos de vida- que habitaban esa capital y elaboraban una agenda social de reivindicaciones.

En síntesis, se trata de un riguroso estudio, con una sugerente aproximación teórica y metodológica a un espacio complejo de interacciones sociales; un estudio situado en una historiografía vigente que instala la ciudad como sujeto que solo se puede comprender en un contexto material, espacial y temporal determinados. Un libro que elabora cómo las implicancias materiales, sociales y simbólicas de la modernización entre cafetales ha definido la forma y desafíos de la ciudad contemporánea. CEURE

\section{Macarena Ibarra.}

Pontificia Universidad Católica de Chile. E-MAIL:MIBARRAA@UC.CL 